\title{
Review Article \\ New Therapeutic Concept of NAD Redox Balance for Cisplatin Nephrotoxicity
}

\author{
Gi-Su Oh, ${ }^{1}$ Hyung-Jin Kim, ${ }^{1}$ AiHua Shen, ${ }^{1}$ Su-Bin Lee, ${ }^{1}$ Sei-Hoon Yang, ${ }^{2}$ Hyeok Shim, \\ Eun-Young Cho, ${ }^{2}$ Kang-Beom Kwon, ${ }^{3}$ Tae Hwan Kwak, ${ }^{4}$ and Hong-Seob So ${ }^{1}$ \\ ${ }^{1}$ Center for Metabolic Function Regulation, Department of Microbiology, School of Medicine, Wonkwang University, \\ Iksan, Jeonbuk 570-749, Republic of Korea \\ ${ }^{2}$ Department of Internal Medicine, School of Medicine, Wonkwang University, Iksan, Jeonbuk 570-749, Republic of Korea \\ ${ }^{3}$ Department of Oriental Medical Physiology, College of Korean Medicine, Wonkwang University, \\ Iksan, Jeonbuk 570-749, Republic of Korea \\ ${ }^{4}$ PAEAN Biotechnology, 160 Tachno-2 Street, Yuseong-gu, Daejeon 305-500, Republic of Korea
}

Correspondence should be addressed to Hong-Seob So; jeanso@wku.ac.kr

Received 22 October 2015; Accepted 9 December 2015

Academic Editor: Jeremiah R. Brown

Copyright (C) 2016 Gi-Su Oh et al. This is an open access article distributed under the Creative Commons Attribution License, which permits unrestricted use, distribution, and reproduction in any medium, provided the original work is properly cited.

Cisplatin is a widely used chemotherapeutic agent for the treatment of various tumors. In addition to its antitumor activity, cisplatin affects normal cells and may induce adverse effects such as ototoxicity, nephrotoxicity, and peripheral neuropathy. Various mechanisms such as DNA adduct formation, mitochondrial dysfunction, oxidative stress, and inflammatory responses are closely associated with cisplatin-induced nephrotoxicity; however, the precise mechanism remains unclear. The cofactor nicotinamide adenine dinucleotide $\left(\mathrm{NAD}^{+}\right)$has emerged as a key regulator of cellular energy metabolism and homeostasis. Recent studies have demonstrated associations between disturbance in intracellular $\mathrm{NAD}^{+}$levels and clinical progression of various diseases through the production of reactive oxygen species and inflammation. Furthermore, we demonstrated that reduction of the intracellular $\mathrm{NAD}^{+} / \mathrm{NADH}$ ratio is critically involved in cisplatin-induced kidney damage through inflammation and oxidative stress and that increase of the cellular $\mathrm{NAD}^{+} / \mathrm{NADH}$ ratio suppresses cisplatin-induced kidney damage by modulation of potential damage mediators such as oxidative stress and inflammatory responses. In this review, we describe the role of $\mathrm{NAD}^{+}$metabolism in cisplatininduced nephrotoxicity and discuss a potential strategy for the prevention or treatment of cisplatin-induced adverse effects with a particular focus on $\mathrm{NAD}^{+}$-dependent cellular pathways.

\section{Introduction}

cis-Diamminedichloroplatinum II (CDDP, cisplatin) is a widely used chemotherapeutic drug for the treatment of various solid tumors in the head and neck, bladder, lung, ovaries, testicles, and uterus [1-6]. The various adverse effects of cisplatin during the course of chemotherapy include ototoxicity, nephrotoxicity, myelosuppression, and peripheral neuropathy. Cisplatin accumulates in renal tissues and cells, which are primary sites for drug filtration, concentration, and excretion. Even if blood concentrations are held at nontoxic levels during chemotherapy, concentrations may reach toxic levels in the kidneys [4]. In general, cisplatin concentrations in tubular epithelial cells of kidney tissues are five times higher than those in blood, and the elevated concentration of cisplatin therein causes nephrotoxicity. Clinical signs of kidney damage are a decrease in renal plasma flow and glomerular filtration rate, an increase of serum creatinine and blood urea nitrogen, and a reduction of serum magnesium and potassium levels [7]. Cisplatin-induced nephrotoxicity is dose-dependent and therefore limits the potential to increase dosage for optimal cancer therapy [8]. Even though the establishment of cisplatin-induced nephrotoxicity can be alleviated by diuretics and prehydration of patients, the prevalence of cisplatin nephrotoxicity is still high, occurring in approximately one-third of patients who have undergone 
cisplatin therapy [6]. Cisplatin nephrotoxicity can present in a number of ways, including acute kidney injury, hypomagnesemia, hypocalcemia, hyperuricemia, distal renal tubular acidosis, proximal tubular dysfunction, and chronic renal failure [7]. However, the most serious and one of the more common clinical features of cisplatin nephrotoxicity is acute kidney injury which occurs in $20-30 \%$ of patients. Recent studies have demonstrated that the cellular process of nephrotoxicity can be attributed to local accumulation of cisplatin inside the proximal tubule by membrane transportation, and intracellular conversion of the drug into toxic metabolites. Furthermore, various mechanisms such as DNA adduct formation, mitochondrial dysfunction, oxidative stress, inflammatory responses, and activation of apoptotic pathways are closely associated with cisplatin-induced nephrotoxicity [7].

The cofactor nicotinamide adenine dinucleotide $\left(\mathrm{NAD}^{+}\right)$ has emerged as a key regulator of cellular energy metabolism and homeostasis. Recently, it has been reported that intracellular $\mathrm{NAD}^{+} / \mathrm{NADH}$ ratios are decreased in various pathological conditions such as diabetes [9], cisplatin-induced cochlear and kidney damage $[10,11]$, and in many tissues of aged animals and humans $[12,13]$. Recent studies have demonstrated that a disturbance in intracellular $\mathrm{NAD}^{+}$levels is linked to the progression of various diseases through the production of reactive oxygen species (ROS) and inflammation $[10,11,14]$. Furthermore, reduction of the intracellular $\mathrm{NAD}^{+} / \mathrm{NADH}$ ratio is critically involved in cisplatin-induced acute kidney damage; increasing the cellular $\mathrm{NAD}^{+} / \mathrm{NADH}$ ratio by pharmacological agents suppresses cisplatin-induced acute kidney damage by downregulation of potential damage mediators such as oxidative stress and inflammatory responses [11]. The decrease in the $\mathrm{NAD}^{+} / \mathrm{NADH}$ ratio has been attributed to hyperactivation of the $\mathrm{NAD}^{+}$-consuming poly(ADP-ribose) polymerase 1 (PARP-1) induced by oxidative damage due to altered redox mechanisms and consequent DNA damage $[10,11]$. Since silent mating type information regulation 2 homolog 1 (sirtuin 1, SIRT1) deacetylase activity is influenced by the $\mathrm{NAD}^{+} / \mathrm{NADH}$ ratio [15], a significant reduction in the $\mathrm{NAD}^{+} / \mathrm{NADH}$ ratio causes a concomitant decrease in SIRT1 deacetylase activity, which is critically involved in diverse biological functions. In addition, the $\alpha$-ketoglutarate dehydrogenase $(\alpha-\mathrm{KGDH})$ complex, an enzyme complex of the Krebs cycle in mitochondria, facilitates the generation of ROS after $\mathrm{NAD}^{+} / \mathrm{NADH}$ reduction [16]. Decreased $\mathrm{NAD}^{+} / \mathrm{NADH}$ also favors ROS generation in the respiratory chain complex I [17]. Therefore, maintenance of adequate $\mathrm{NAD}^{+}$levels may be a critical factor for normal cellular function and could emerge as a useful strategy for treating many diseases.

Although there are review articles each focusing on cisplatin-mediated nephrotoxicity or beneficial role of $\mathrm{NAD}^{+}$, there is lack of effort illustrating a potential therapeutic or preventive strategy of modulatory $\mathrm{NAD}^{+}$levels for treating cisplatin-associated nephrotoxicity. Therefore, we aimed to review a critical issue related to cisplatin-induced nephrotoxicity which can potentially be overcome by modulation of cellular $\mathrm{NAD}^{+}$levels. We searched PubMed for published articles using separate search terms "cisplatin-mediated nephrotoxicity" and "NAD ${ }^{+}$-modulation and disease" and included only most recent and relevant publication including original research articles and reviews but excluded repetitive illustrations. In this review, we describe the mechanisms of cisplatin-mediated nephrotoxicity and the role of $\mathrm{NAD}^{+}$ metabolism therein and discuss a potential strategy for prevention of the adverse effects of cisplatin through targeting of $\mathrm{NAD}^{+}$-dependent cellular pathways.

\section{Kidney-Specific Toxicity of Cisplatin: Cisplatin Transport and Biotransformation}

Cisplatin is primarily cleared by the kidneys through both glomerular filtration and tubular secretion, whereas the biliary and intestinal excretions of this drug are negligible. During the excretion process, cisplatin is highly concentrated in the kidneys, which suggests an active accumulation of this drug by renal parenchymal cells, thereby explaining the particular damage caused by this drug to the kidneys compared to other organs. The toxic effects of cisplatin occur primarily in the renal proximal tubules, predominantly in the epithelial tubular cells of the S-3 segment [18]. Though the high concentrations of cisplatin in the kidneys favor its cellular uptake by passive diffusion, recent studies have demonstrated two different membrane transporters capable of facilitating the transport of cisplatin into cells. Copper transporter 1 (Ctrl) is highly expressed and localized in the basolateral membrane of the proximal tubule in the adult kidney [19]. Even though the role of Ctr1 in cisplatin nephrotoxicity in vivo has not been examined, cisplatin uptake and cytotoxicity were decreased by downregulation of Ctr1 expression in kidney cells in vitro, suggesting that Ctr1 is required for cisplatin uptake in these cells. In addition, the organic cation transporter 2 (OCT2) is specifically expressed in the basolateral membranes of the kidney renal proximal tubule cells, contributing to the etiology of the organspecific toxicity of cisplatin. OCT2 expression is critical for the development of cisplatin-induced nephrotoxicity, and introduction of the OCT2 substrate cimetidine, a competing factor for transport, reduces nephrotoxicity [20], suggesting that OCT2 is critically involved in cisplatin uptake and its toxicity in these cells. In addition to specific expression of cisplatin transporter proteins in the kidney, many studies have demonstrated that cisplatin undergoes metabolic activation in the kidney to a more potent nephrotoxin. This process is initiated with the biotransformation of cisplatin-glutathione (GSH) conjugates by glutathione-S-transferase in the circulation [21]. When the cisplatin-GSH conjugate reaches and passes through the kidney, it is cleaved to a nephrotoxic metabolite primarily by the action of gamma-glutamyl transpeptidase, an enzyme principally located on the surface of the kidney proximal tubule cells. This metabolite is a highly reactive thiol/platinum compound that interacts with macromolecules, eventually leading to renal damage [22].

\section{Mechanisms of Cisplatin Nephrotoxicity}

3.1. Oxidative Stress in Cisplatin Nephrotoxicity. Oxidative stresses, including superoxide anions, hydrogen peroxide, and hydroxyl radicals, are unavoidable by-products of cellular respiration. Oxidative stress is also closely involved 
in renal injury after cisplatin administration. In particular, production of ROS and antioxidant system dysfunction are associated with cisplatin-induced nephrotoxicity [23]. Due to their unstable and highly reactive nature, ROS may attack and modify multiple target molecules such as lipids, proteins, and DNA, producing cellular stress. ROS also activate important signaling pathways, including an apoptotic pathway, which leads to cell death in the event of cisplatin-induced nephrotoxicity [24]. Although the role of oxidative stress in renal damage is well established, its source is poorly understood. Potential sources of ROS include the mitochondrial electron transport chain system [25], xanthine oxidase [26], cytochrome P450 enzymes [27], and NADPH oxidase [28]. Cisplatin may produce ROS in microsomes via the cytochrome $\mathrm{P} 450$ system (CYP). In vitro and in vivo tests have demonstrated that CYP is an important source of catalytic iron for the generation of ROS during cisplatin treatment. Furthermore, the cisplatin-induced increase of ROS and kidney damage were attenuated in $\mathrm{CYP}_{2} \mathrm{E}^{-/-}$mice [29]. Mitochondria have also been reported to be a major source of ROS. Disturbance of the mitochondrial electron transport chain system, which was accompanied by loss of mitochondrial membrane potential, an indicator of mitochondrial dysfunction, is a well-recognized mechanism responsible for the generation of ROS [25]. Interestingly, mitochondria themselves are particularly vulnerable to oxidative stress. Oxidative damage to mitochondria causes the impairment of mitochondrial function and subsequent cell death via apoptosis and necrosis [30]. Thus, ROS-mediated oxidative damage to mitochondria favors the generation of additional ROS, resulting in a vicious cycle. Many studies have demonstrated a clear association between mitochondrial ROS generation and cisplatin nephrotoxicity [6]. Membrane NAD(P)H oxidases (NOXs) are also one of the major sources for ROS generation. Especially in phagocytic cells such as neutrophils, superoxide is generated by NOX enzyme complexes [31]. However, many studies have recently found that superoxide-generating NOX expression is not restricted to phagocytic cells but is present in a wide variety of nonphagocytic cells and tissues [32]. In particular, it has been reported that superoxidegenerating NOXs are expressed in the inner ear and in kidney tissues and that their expression is increased by exposure to cisplatin, thereby causing oxidative stress that leads to cisplatin-mediated ototoxicity and nephrotoxicity $[11,33,34]$.

3.2. Inflammation in Cisplatin Nephrotoxicity. In addition to direct cellular toxicity, inflammation is closely associated with the pathogenesis of cisplatin nephrotoxicity. Over the last decade, it has been found that a number of mediators of inflammation, including TNF- $\alpha$, IL- $1 \beta$, TGF- $\beta$, RANTES, MIP2, and MCP1, are increased in cisplatin-induced renal injury. Inflammation contributes to the development of renal tissue damage and renal failure under pathological conditions. However, evidence for a functional role in renal damage for many of these cytokines still remains to be identified, with the exception of TNF- $\alpha[35,36]$. The proinflammatory cytokine TNF- $\alpha$ plays a central role in many infectious and inflammatory diseases. Relevantly, the functional involvement of TNF- $\alpha$ in the pathogenesis of cisplatin-induced acute renal failure was determined in mice treated with cisplatin in the presence or absence of TNF- $\alpha$ production inhibitors, as well as in TNF- $\alpha$ knockout mice. Treatment with TNF- $\alpha$ production inhibitors reduced cisplatin-induced renal damage and also reduced histologic evidence of injury. TNF-deficient mice were also resistant to cisplatin nephrotoxicity. These results indicated an important role for TNF- $\alpha$ in the pathogenesis of cisplatin nephrotoxicity [37]. Furthermore, this study showed that pharmacological inhibitors and antibodies against TNF- $\alpha$ markedly suppressed the induction of other cytokines during cisplatin nephrotoxicity, suggesting that TNF- $\alpha$ might be a key upstream regulator of the inflammatory response triggered by cisplatin. These observations have been confirmed and extended by other studies [38-40]. TNF$\alpha$ can be produced by a variety of both immune and nonimmune cells. However, Zhang et al. were able to determine the source of the TNF- $\alpha$ that was responsible for cisplatininduced renal damage [39]. They created chimeric mice in which TNF- $\alpha$ could be produced by resident kidney cells or by circulating immune cells and evaluated kidney function, histology, and cytokine expression in these chimeric mice following cisplatin administration. In this study, they demonstrated that the local production of TNF- $\alpha$ by resident kidney cells, probably the renal epithelial cells themselves, was crucial to cisplatin-induced nephrotoxicity [39].

The next question, then, became: how does TNF- $\alpha$ stimulate the inflammatory response and contribute to cisplatin nephrotoxicity? The biological activities of TNF- $\alpha$ are primarily mediated by two functionally distinct receptors, TNFR1 and TNFR2, to induce a variety of cellular responses ranging from inflammation to cell death. TNFR1 and TNFR2 are also upregulated by cisplatin. While TNFR1 directly induces the extrinsic apoptotic pathway, TNFR2 is primarily associated with the inflammatory response, which amplifies the TNFR1 effects. Furthermore, as the TNFR2 protein does not contain the death domain necessary to trigger apoptosis, TNFR2, unlike TNFR1, would appear to indirectly induce apoptosis and necrosis in renal tubular epithelial cells [41, 42]. Conflictingly, Tsuruya et al. showed that TNFR1-deficient mice and renal tubular cells were more resistant to cisplatin-induced renal injury and apoptosis compared with wild type mice [43], whereas Ramesh and Reeves recently showed that cisplatin-induced tubular cell death and renal injury were clearly attenuated in TNFR2deficient, but not in TNFR1-deficient, mice [41]. Although the cause of the inconsistency between these two studies has not been elucidated, together they suggest that TNF- $\alpha$ signaling plays a critical role for cisplatin nephrotoxicity. The production of TNF- $\alpha$ after cisplatin administration is highly dependent upon ROS, NF- $\kappa \mathrm{B}$ activation, and activation of p38 MAPK. In fact, TNF- $\alpha$ both is an inducer of ROS and is induced by ROS generated by cisplatin [37]. ROS activates the transcription factor $\mathrm{NF}-\kappa \mathrm{B}$, which in turn induces the production of proinflammatory cytokines such as TNF- $\alpha$ [42]. NF- $\kappa \mathrm{B}$ activation is pivotal in the expression of proinflammatory cytokines and other mediators involved in acute inflammatory responses and other conditions associated with increased ROS generation [44]. In addition to direct oxidative damage to lipids, DNA, and proteins [23], ROS generated 
by cisplatin activates p38 MAPK through the induction of p38 MAPK phosphorylation, which mediates the synthesis of TNF- $\alpha$. Ramesh and Reeves demonstrated that inhibition of p38 MAPK reduced TNF- $\alpha$ production and protected against cisplatin-induced renal damage in vivo [45]. Activation of p38 MAPK led to the degradation of $\mathrm{I} \kappa \mathrm{B}$ (an inhibitor of NF$\kappa \mathrm{B})$, thereby promoting translocation of NF- $\kappa \mathrm{B}$ to the nucleus and the consequent stimulation of proinflammatory cytokine production, including TNF- $\alpha$ [46].

Toll-like receptors (TLRs) are a family of pattern recognition receptors that detect pathogenic elements such as viral RNA, bacterial DNA, lipopolysaccharides, or proteins, called pathogen-associated molecular patterns (PAMPs). TLRs play a pivotal role in host defense against infection by sensing the invasion of organisms and initiating both innate and adaptive immune responses [47]. TLRs also detect and respond to certain endogenous molecules such as high-mobility group box protein 1 (HMGB1), heat shock proteins (HSPs), and extracellular matrix components, termed damage-associated molecular pattern molecules (DAMPs). DAMPs are generally released by damaged or stressed tissues to "alert" the immune system to tissue injury or impending danger [48]. Cisplatin increases the expression of TLRs, including TLR4 in murine peritoneal macrophages in vitro, and subsequent stimulation by individual TLR-related ligands induces the production of proinflammatory cytokines such as TNF- $\alpha$, IFN- $\gamma$, IL- $1 \beta$, and IL-12 [49]. In addition, Zhang et al. have demonstrated that TLR4 is essential to the initiation of intrarenal inflammatory cytokine production associated with cisplatin-induced nephrotoxicity [50]. Ramesh et al. also have demonstrated that the combination of cisplatin and lipopolysaccharides, which are specific ligands for TLR4, acts synergistically to produce inflammatory cytokines such as TNF- $\alpha$, IL-6, MCP$1, \mathrm{KC}$, and GM-CSF, thereby inducing nephrotoxicity in an acute renal failure model [51].

$\mathrm{NF}-\kappa \mathrm{B}$ activation is a critical bridge to the expression of inflammatory cytokines and other mediators involved in inflammatory responses through TLR signaling. After dimerization of TLR4 through engagement with its ligand, adapter molecules such as TIRAP and TRAM are recruited on the cytoplasmic domain of TLR4, which further interacts with MyD88 and TRIF, respectively, and then transduces a signal to the nucleus. MyD88 is critical for signaling by all TLRs except TLR3. After stimulation, MyD88 associates with the cytoplasmic portion of the TLR and recruits IL-1R-associated kinase- (IRAK-) 4 and -1 through a homophilic interaction of the death domains. Subsequently, TRAF6, TAK1, and NF- $\kappa$ B are activated, and then NF- $\kappa \mathrm{B}$ is translocated into the nucleus where it regulates the genes for proinflammatory cytokines among others [52]. In contrast, in TLR4 knockout mice, the activation of p38, which is critical for cisplatin-induced TNF- $\alpha$ production, was significantly blunted [45]. Finally, the released nuclear protein HMGB1 has been shown to activate TLR4 in various pathologic conditions $[48,53]$; however, the role of HMGB1 and other DAMPs in TLR4 activation associated with cisplatin nephrotoxicity remains to be elucidated.

3.3. Role of NAD Redox Balance in Cisplatin Nephrotoxicity. NAD is a metabolic cofactor that is present in cells either in its oxidized $\left(\mathrm{NAD}^{+}\right)$or in its reduced $(\mathrm{NADH})$ form. $\mathrm{NAD}^{+}$ or NADH functions as a cofactor for a multitude of enzymatic reactions and therefore critically regulates cellular energy metabolism and homeostasis. As $\mathrm{NAD}^{+}$is critical for a variety of enzymatic reactions, including glycolysis, the NAD redox balance, represented as the $\mathrm{NAD}^{+} / \mathrm{NADH}$ ratio, is tightly regulated [54], and its disruption has been associated with multiple clinical disorders and pathologies. For example, pellagra is caused by $\mathrm{NAD}^{+}$deficiency subsequent to poor dietary intake of $\mathrm{NAD}^{+}$biosynthesis precursors and can be easily cured by providing dietary nicotinic acid [55]. Pathological conditions such as diabetes and oxidative stress are also well correlated with decreased cellular $\mathrm{NAD}^{+}$levels $[9,56]$. It has also been recently reported that the cellular $\mathrm{NAD}^{+}$level in many tissues declines with age $[12,13]$, implying the importance of maintaining optimal intracellular $\mathrm{NAD}^{+}$levels to prevent age-associated cellular dysfunction. Furthermore, cisplatininduced cochlear and kidney damage are highly associated with the decreases of $\mathrm{NAD}^{+} / \mathrm{NADH}$ ratios that accompany inflammation and oxidative stress $[10,11]$. Cisplatin treatment resulted in a decrease of $\mathrm{NAD}^{+} / \mathrm{NADH}$ ratio in renal tissue without significant changes of NADH level [11]. This suggests that the decrease of $\mathrm{NAD}^{+} / \mathrm{NADH}$ ratio by cisplatin is mainly caused by reduction of $\mathrm{NAD}^{+}$level. Of note, $\beta$-lapachone coadministration with cisplatin also restored $\mathrm{NAD}^{+} / \mathrm{NADH}$ ratio to control level through elevation of $\mathrm{NAD}^{+}$level, but not by decrease of NADH level. Together, these findings suggest that maintenance of the NAD redox balance is very important for general health.

\subsection{Role of $\mathrm{NAD}^{+}$-Dependent Enzymes in Cisplatin Nephro-} toxicity. $\mathrm{NAD}^{+}$acts as a cofactor for numerous enzymes including SIRTs, PARPs, and cyclic ADP- (cADP-) ribose synthases [57]; therefore, $\mathrm{NAD}^{+}$might exert its biological effect through these enzymes. The mammalian sirtuin family consists of seven enzymes, SIRT1-7 [58], that are ubiquitously expressed yet show specific cellular localizations and functions. SIRT1, SIRT6, and SIRT7 are generally localized in the nuclei of cells, whereas SIRT3, SIRT4, and SIRT5 are localized in the mitochondria [59]. SIRT1 and SIRT5 act exclusively as deacetylases [60, 61], whereas SIRT2, SIRT3, SIRT4, and SIRT6 might also have a mono-ADP-ribosyl transferase activity [60, 62-64]. SIRT1 is the most widely studied sirtuin and has a $\mathrm{Km}$ for $\mathrm{NAD}^{+}$that lies within the range of the physiological changes in intracellular $\mathrm{NAD}^{+}$ content. This suggests that sirtuin activity could be modulated by the physiological changes in intracellular $\mathrm{NAD}^{+}$levels [64]. Considering that the intracellular $\mathrm{NAD}^{+} / \mathrm{NADH}$ ratios are decreased in various pathological conditions, including cisplatin-induced nephrotoxicity and ototoxicity [9-11, 56], SIRT1 activity might be reduced in the damaged tissues as well. In particular, Hasegawa et al. demonstrated that SIRT1 protects against oxidative stress-induced apoptosis in the kidney by inducing catalase, which catalyzes the decomposition of the ROS hydrogen peroxide, via deacetylation of FOXO3 in cultured proximal tubular cells [65]. Furthermore, Hasegawa et al. also reported that renal proximal tubular cell-specific SIRT1 transgenic mice showed resistance to cisplatin-induced renal tubular cell injuries such as apoptosis by maintaining 
peroxisome number and function, concomitant with upregulation of catalase and elimination of renal ROS [66]. In addition, it has been demonstrated that SIRT1 activation by resveratrol reduced cisplatin-induced proximal tubular cell apoptosis through deacetylation of p53 [67]. In contrast, Kim et al. and $\mathrm{Oh}$ et al. demonstrated that the reduction of intracellular $\mathrm{NAD}^{+} / \mathrm{NADH}$ ratio in cisplatin-injected kidney and cochlear tissues was critically associated with the decline of SIRT1 activity, which thereby caused cisplatin-induced nephrotoxicity and ototoxicity through inflammation and oxidative stress $[10,11]$. However, SIRT1 activation through the increase of the cellular $\mathrm{NAD}^{+} / \mathrm{NADH}$ ratio suppressed the adverse effects of cisplatin by downregulation of potential damage mediators such as oxidative stress factors and inflammatory responses.

SIRT1 regulates diverse biological functions through direct interaction with and subsequent deacetylation of its targets, including p53 and NF- $\kappa \mathrm{B}$, which are closely related to its function in cisplatin-induced nephrotoxicity [7]. As described previously, the transcription factor $\mathrm{NF}-\kappa \mathrm{B}$ is one of the key regulators of inflammation. NF- $\kappa \mathrm{B}$ activation is attained by either $\mathrm{I} \kappa \mathrm{B}$ phosphorylation and subsequent degradation or an $\mathrm{I} \kappa \mathrm{B}$-independent pathway through posttranslational modifications of the NF- $\kappa$ B Rel proteins, including acetylation of the NF- $\kappa \mathrm{B}$ p 65 subunit. NF- $\kappa \mathrm{B}$ p 65 can be acetylated at five specific lysine residues (Lys-122, Lys-123, Lys-218, Lys-221, and Lys-310). In particular, acetylation of the Lys-310 residue is required for the transcriptional activity of NF- $\kappa \mathrm{B}$, whereas the other acetylation sites are involved in DNA binding [68]. SIRT1 physically interacts with the nuclear translocated NF- $\kappa \mathrm{B}$ p 65 subunit and deacetylates it at Lys-310, thereby inhibiting the transcriptional activity of NF- $\kappa \mathrm{B}$ [69]. An assortment of recent evidence indicates that SIRT1 regulates inflammatory response through NF- $\kappa \mathrm{B}$ p65 deacetylation. In cisplatin-induced nephrotoxicity and ototoxicity, Kim et al. demonstrated that SIRT1 activation was critically associated with the deacetylation status of the NF$\kappa \mathrm{B}$ p65 subunit $[10,11]$. In addition, it has been demonstrated that SIRT1 knockdown leads to inflammatory pathway activation with increased inflammatory gene expression, whereas SIRT1 activation produces anti-inflammatory effects [70].

The tumor suppressor p53 is another crucial transcription factor in the cellular stress response [71]. A number of posttranslational modifications can occur in p53 that have critical effects on its stability and function, including phosphorylation, acetylation, sumoylation, neddylation, and methylation [72]. Cytosolic p53 is bound to Mdm2, a RING finger E3 ubiquitin ligase that facilitates protein degradation under normal conditions. Cellular stress, including DNA damage, hypoxia, or oxidative stress, induces rapid mitochondrial translocation of p53 and its posttranslational modification such as acetylation by p300/CBP or PCAF acetyltransferase [73]. The p53 is acetylated at lysine residues, including Lys370, Lys-372, Lys-382, and Lys-386 in the carboxy-terminal region. Because acetylated p53 cannot bind to $\mathrm{Mdm} 2$, increased p53 acetylation levels strongly correlate with protein stabilization and activation in response to cellular stress [74]. Both nuclear SIRT1 and mitochondrial SIRT3 regulate p53 function through direct interaction and subsequent deacetylation of p53 [75]. In the nucleus, acetylation of p53 stimulates its sequence-specific DNA binding and subsequent recruitment of other transcription cofactors to promoter regions and thereby enhances transcription of target genes [76-78] such as the p53-upregulated modulator of apoptosis (PUMA), NADPH activator A (NOXA), and p53-induced gene 3 (PIG3), all of which are involved in the production of ROS through mitochondrial dysfunction or apoptosis. Deacetylation of p53 by nuclear-localized SIRT1 inactivates its sequence-specific transcriptional activity and represses p53mediated cell growth arrest and apoptosis in response to DNA damage and oxidative stress [74]. Mitochondrial-localized SIRT3 deacetylates and activates several enzymes that are critical in maintaining cellular ROS levels and for apoptosis. Though it is not well understood whether acetylated p53 in mitochondria might have other functions, mitochondrial p53 interacts with anti- and proapoptotic Bcl-2 family members to either inhibit or activate them, thereby promoting apoptosis through robust mitochondrial outer membrane permeabilization and subsequent cytochrome c release [79, 80]. Deacetylation of p53 by mitochondrial-localized SIRT3 also represses p53-mediated cell growth arrest and apoptosis in response to DNA damage and oxidative stress [75]. On the other hand, Kim et al. demonstrated that cisplatin treatment led to substantial elevation of acetylated p53 levels in the kidney and cochlear tissues compared to those of untreated normal control mice $[10,11]$.

$\mathrm{NAD}^{+}$is consumed not only by sirtuins, but also by PARPs [81]. Cisplatin accumulation in target tissues produces ROS that deplete the cellular antioxidant defense factors necessary to reduce oxidative stress and DNA damage. Cisplatin also directly binds to DNA, resulting in the disruption of the synthesis of key proteins and leading to cell injury and cell death. Furthermore, accumulation of DNA damage can lead to cell cycle arrest or genomic instability. The removal of DNA damaged by oxidative stress is mediated by single-strand DNA break repair, which is facilitated by PARPs. PARP-1 is the most critical protein-modifying nuclear enzyme involved in DNA repair. PARP-1 is a major $\mathrm{NAD}^{+}$ consumer, wherein the ADP-ribose moiety is transferred to PARP-1 itself or to other acceptor proteins in order to build the poly(ADP-ribose) polymer (PAR) [82]. PARP-1 is strongly activated by DNA damage and oxidative stress. Under physiological conditions, mild activation of PARP-1 can regulate several cellular processes, including DNA repair, cell cycle progression, cell survival, chromatin remodeling, and genomic stability [83]. However, hyperactivation of PARP-1 upon severe oxidative damage causes rapid depletion of intracellular $\mathrm{NAD}^{+}$and ATP levels and eventually leads to cell death and related pathological conditions [84, 85]. Kim et al. have demonstrated that hyperactivation of PARP1 in cisplatin-treated cochlea led to a decline in intracellular $\mathrm{NAD}^{+}$levels and SIRT1 activity, thereby causing cochlear damage [10]. It is well established that PARP-1 and SIRT1 activity are interdependent as they compete for a limited pool of cellular NAD ${ }^{+}$. However, the Km of PARP- 1 for $\mathrm{NAD}^{+}$is two to ten times lower than that of SIRT1, which falls within the physiological range of cellular $\mathrm{NAD}^{+}$concentrations [86]. Thus, PAPR-1 activation might critically influence SIRT1 

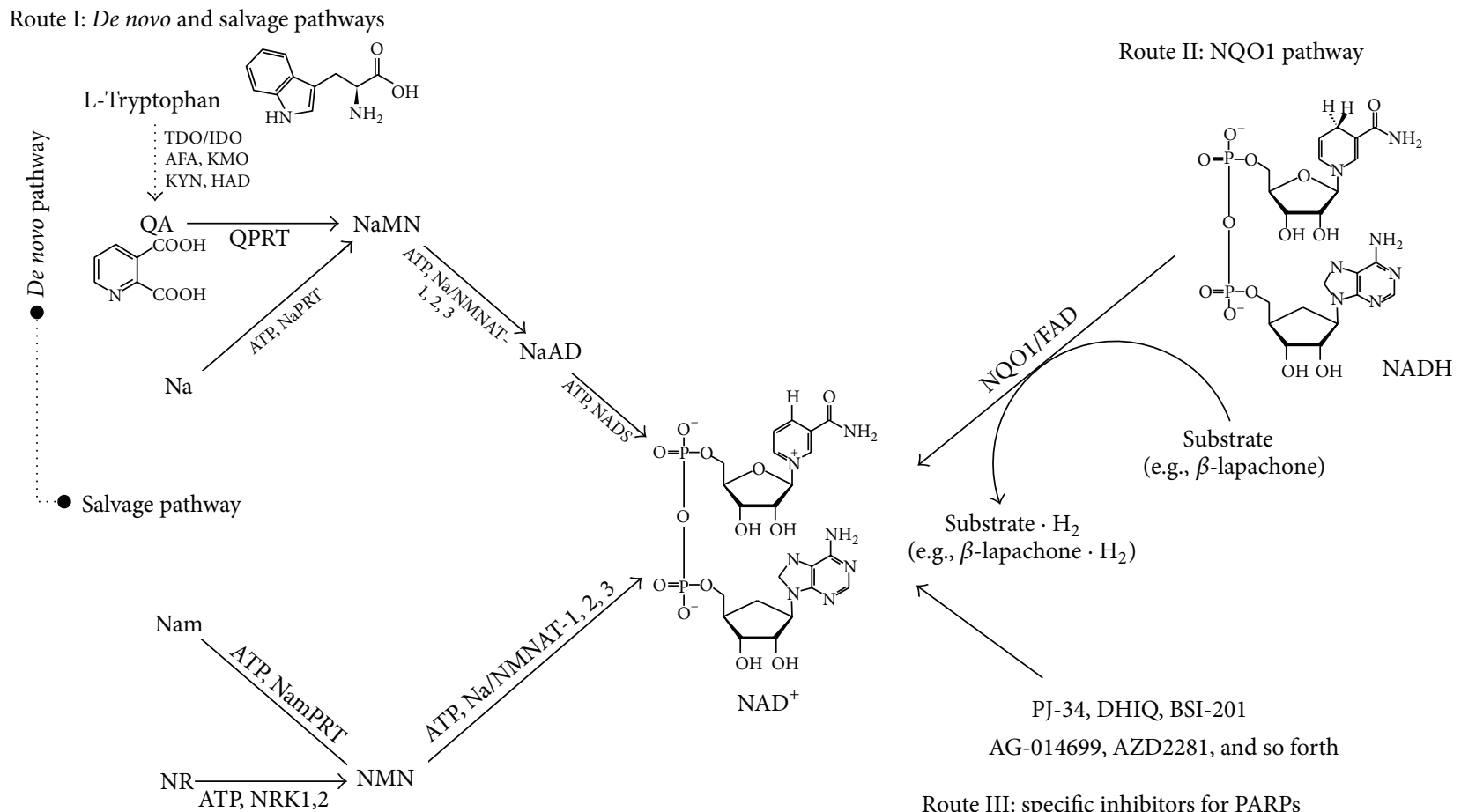

Route III: specific inhibitors for PARPs

FIgURE 1: Possible pathways for mammalian $\mathrm{NAD}^{+}$biosynthesis. The biosynthesis of $\mathrm{NAD}^{+}$through de novo, salvage, NQO1 pathways, and specific inhibition for PARPs. ATP: adenosine triphosphate, FAD: flavin adenine dinucleotide, IDO: indoleamine 2,3-dioxygenase, $\mathrm{Na}$ : nicotinic acid, NaAD: nicotinic acid adenine dinucleotide, NAD: nicotinamide adenine dinucleotide, NADS: NAD synthetase, Nam: nicotinamide, NaMN: nicotinic acid mononucleotide, NaPRT: nicotinic acid phosphoribosyl transferase, NMN: nicotinamide mononucleotide, NMNAT: nicotinamide mononucleotide adenylyltransferase, NQO1: NAD(P)H:quinone oxidoreductase 1, NR: nicotinamide riboside, NRK1,2: nicotinamide riboside kinase 1, 2, NamPRT: nicotinamide phosphoribosyltransferase, NMNAT: nicotinamide mononucleotide adenyltransferase, QA: quinolinic acid, QPRT: quinolinate phosphoribosyltransferase, TDO: tryptophan 2,3-dioxygenase, AFA: arylformamidase, KMO: kynurenine 3-monooxygenase, KYN: kynureninase, HAD: 3-hydroxy-anthranilate 3,4-dioxygenase, and PARPs: poly(ADP-ribose) polymerases.

activity by reducing $\mathrm{NAD}^{+}$bioavailability. This model was further supported by recent studies wherein genetic depletion of PARP-1 or pharmacological inhibition of PARP-1 activity increased intracellular $\mathrm{NAD}^{+}$level and subsequent SIRT1 activity [10].

\section{Therapeutic Considerations of Cisplatin Nephrotoxicity}

The main protective actions currently employed in clinical practice to reduce nephrotoxicity during cisplatin chemotherapy are based on avoiding the extreme exposure of the kidneys to the drug. This is managed primarily by hydration/diuretics, monitoring of renal function by serum creatinine clearance, and decreasing cisplatin doses upon manifestation of renal dysfunction [87, 88]. However, even with aggressive hydration, renal toxicity occurs. Therefore, more effective preventative strategies without attenuation of tumoricidal activity need to be developed, taking into consideration the mechanisms underlying the adverse effects of cisplatin exposure. Although the exact mechanism responsible for cisplatin-associated cellular damage is still to be elucidated, numerous studies have indicated that ROS and increased inflammation are important factors. The roles of these two factors seem to be closely related, and thus their abnormal regulation impacts overlapping cellular processes. Accordingly, pharmacological interventions that reduce systemic inflammation and/or oxidative stress might prevent or alleviate the development and progression of cisplatininduced nephrotoxicity. However, these effects need to be explored in vivo [7]. A better option might be to focus on maintaining a proper level of intracellular $\mathrm{NAD}^{+}$. The decrease of cellular $\mathrm{NAD}^{+}$level in the kidney and cochlear tissues after cisplatin exposure $[10,11]$ implies the therapeutic potential of intracellular $\mathrm{NAD}^{+}$level modulation for cisplatin-associated adverse effects. The role of $\mathrm{NAD}^{+}$in the prevention and cure of diseases was first recognized in the 1930s by Conrad Elvehjem, who demonstrated the therapeutic effect of the vitamin nicotinic acid on pellagra in dogs [55]. Since then, the therapeutic potential of $\mathrm{NAD}^{+}$ has been further evidenced by several studies. Araki et al. showed that addition of exogenous $\mathrm{NAD}^{+}$to neurons delayed axonal degeneration in response to mechanical or chemical damage [89]. Ying et al. also demonstrated that intranasal administration of $\mathrm{NAD}^{+}$profoundly decreased brain injury in a rat model of transient focal ischemia [90]. Pillai et al. showed that exogenous $\mathrm{NAD}^{+}$blocked cardiac hypertrophic response [91]. 
<smiles>COC1C(=O)C(CC=C(C)C)=C(C)C(OC)C1=O</smiles>

Ubiquinones $(n=1 \sim 10)$<smiles></smiles>

Pyrroloquinoline quinone (PQQ)

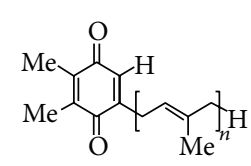

Plastoquinones $(n=1 \sim 10)$

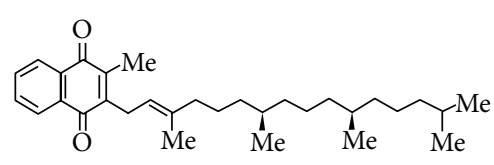

Phylloquinone (vitamin $\mathrm{K}_{1}$ )

(a)<smiles>COC1=C(OC)C(=O)C(CCCCCCCCCCO)=C(C)C1=O</smiles>

Idebenone<smiles>COC1=C(OC)C(=O)C(CCCCCCCCCC(=O)O)=C(C)C1=O</smiles>

QS-10<smiles>O=C1C=CC=CC1=O</smiles>

$o$-Benzoquinones<smiles>O=C1C=CC(=O)C=C1</smiles><smiles>O=C1C=CC(=O)c2ccccc21</smiles><smiles></smiles>

-Benzoquinones Naphthoquinones Quinoneimines<smiles>[M]C1=C(CCC(C)(O)CCCC([M])CCCC([M])CCCC(C)C)C(=O)C(C)=C(C)C1=O</smiles>

$\alpha$-Tocopherolquinone

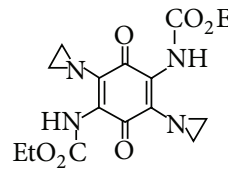

AZQ<smiles>CC1=C(C2CC2)C(=O)C(C2CC2)=C(C)C1=O</smiles>

MeDZQ<smiles>CC1=C(C2CC2)C(=O)C(CO)=C(C#N)C1=O</smiles>

RH1<smiles>CC1(C)CCC2=C(O1)c1ccccc1C(=O)C2=O</smiles>

$\beta$-Lapachone

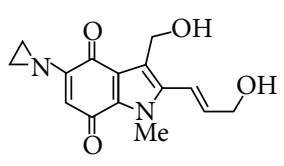

EO9 (indolequinone)

(b)

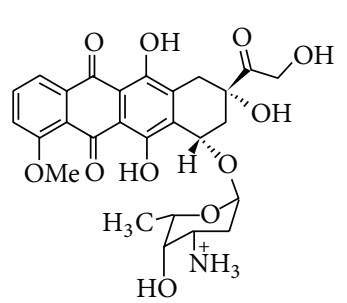

Doxorubicin (adriamycin)

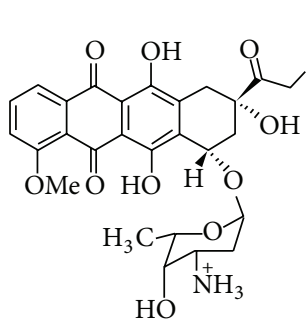

Daunorubicin (daunomycin)

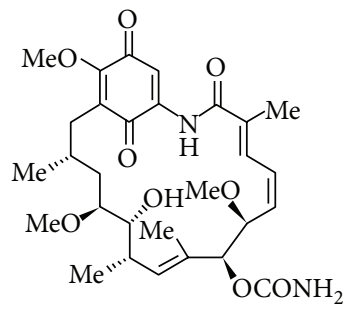

Geldanamycin<smiles>COC12NC1CN1C3=C(C(=O)C(N)=C(C)C3=O)[C@H](COC(C)=O)[C@]12O</smiles><smiles>COC1=C(N)C(=O)c2nc(-c3nc(C(=O)O)c(C)c(-c4ccc(OC)c(OC)c4O)c3N)ccc2C1=O</smiles>

Mitomycin C (MMC)

Streptonigrin

(c)

FIGURE 2: Substrates for NQO1. (a) Naturally occurring quinones as antioxidants. (b) Substrates for reduction by NQO1 and reactive quinone metabolites (benzoquinone, naphthoquinone, and quinoneimine). (c) Naturally occurring quinones with anticancer properties. QS-10: 6(9-carboxynonyl)-2,3-dimethoxy-5-methyl-1,4-benzoquinone, AZQ: Diaziquine, MeDZQ: 2,5-diaziridinyl-3,6-dimethyl-1,4-benzoquinone, and RH1: 2,5-diaziridinyl-3-hydroxymethyl-6-methyl-1,4-benzoquinone.

As $\mathrm{NAD}^{+}$regulates SIRTs that are involved in various cellular processes, the beneficial effects observed following enhanced SIRT activity might be attributed to increased intracellular $\mathrm{NAD}^{+}$levels. Since both PARPs and SIRTs are $\mathrm{NAD}^{+}$-consuming enzymes and thus compete for $\mathrm{NAD}^{+}$, selective blockage of $\mathrm{NAD}^{+}$-consuming PARPs might also potentially be a good strategy to increase $\mathrm{NAD}^{+}$levels. Consistent with this notion, targeted PARP inactivation has been shown to increase $\mathrm{NAD}^{+}$levels and increase SIRT1 activity [92], suggesting that the modulation of PARP activity could be a therapeutic strategy for the treatment of cisplatinassociated adverse effects. In addition, approaches aimed at increasing $\mathrm{NAD}^{+}$levels by supplementing $\mathrm{NAD}^{+}$precursors through the activation of de novo and salvage pathways (Figure 1) for $\mathrm{NAD}^{+}$biosynthesis have demonstrated cytoprotective effects against cellular damage. In fact, this specific strategy has been shown to increase $\mathrm{NAD}^{+}$levels both in vitro and in vivo. For example, the administration of nicotinamide, a NAD ${ }^{+}$precursor, showed a protective effect against oxidative stress and glucose deprivation in vitro and also alleviated tissue damage in animal models of ischemia $[93,94]$, spinal cord injury [95], and multiple sclerosis [96]. Similarly, nicotinic acid, another $\mathrm{NAD}^{+}$precursor, has also been used to treat hyperlipidemia [97], indicating the therapeutic potential of $\mathrm{NAD}^{+}$precursors. Although $\mathrm{NAD}^{+}$treatment has not been tested extensively for its cytoprotective effects, a recent report suggested that it might reduce brain damage by protecting against PARP-1-induced cell death $[98,99]$.

As shown in Figure 1, another strategy in addition to de novo and salvage $\mathrm{NAD}^{+}$biosynthesis pathways for regulating cellular $\mathrm{NAD}^{+}$levels might be to utilize the cytosolic flavoprotein $\mathrm{NADH}$ : quinone oxidoreductase 1 (NQO1) that normally participates in reduction of quinone compounds in exchange for NADH oxidation $[100,101]$. NQO1 catalyzes the reduction of quinones to hydroquinones by utilizing $\mathrm{NADH}$ as an electron donor, which consequently increases intracellular $\mathrm{NAD}^{+}$levels. Therefore, it is plausible that endogenous factors or chemical agents that potentially activate NQO1 


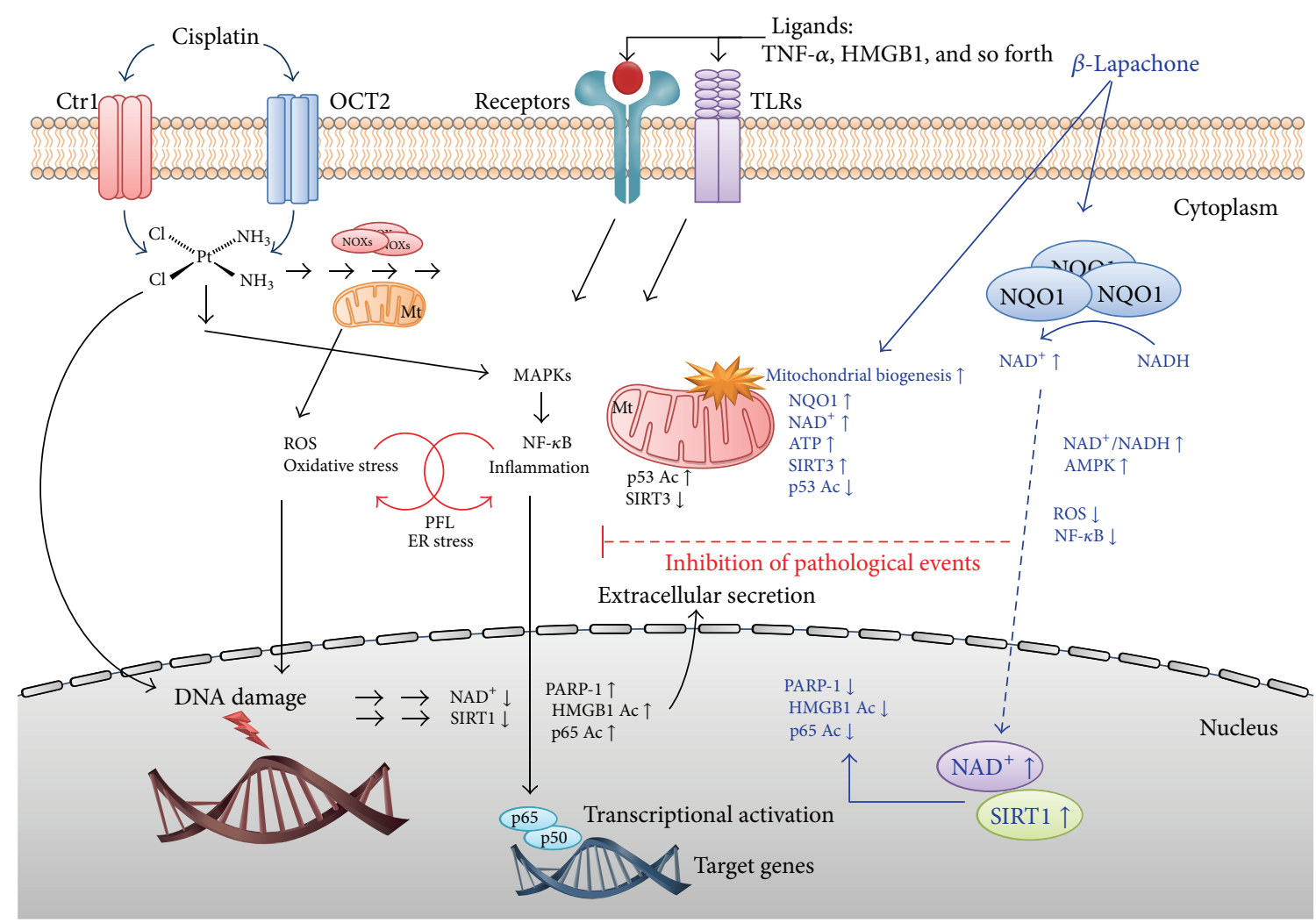

FIGURE 3: Role of $\mathrm{NAD}^{+}$and $\mathrm{NAD}^{+}$-dependent enzymes in cisplatin-induced nephrotoxic mechanisms. Ctrl: copper transporter 1, OCT2: organic cation transporter 2, NOXs: NADPH oxidoreductases, Mt: mitochondria, ROS: reactive oxygen species, PFL: positive feedback loop, ER: endoplasmic reticulum, TLRs: toll-like receptors, HMGB1: high-mobility group box protein 1 , TNF- $\alpha$ : tumor necrosis factor- $\alpha$, NF- $\kappa$ B: nuclear factor- $\kappa \mathrm{B}$, NQO1: NAD(P)H:quinone oxidoreductase 1, and PARPs: poly(ADP-ribose) polymerases.

enzymatic activity or act as strong substrates of NQO1 might be beneficial for protection against cisplatin-induced toxicity by increasing intracellular $\mathrm{NAD}^{+}$levels. In addition, there is evidence that NQO1 also plays a role in other biological activities, including anti-inflammatory processes, the scavenging of superoxide anion radicals, and the stabilization of p53 and other tumor suppressor proteins [102-106]. As shown in Figure 2, several substrates of NQO1 enzyme, including mitomycin C, RH1, AZQ, Coenzyme Q10, and idebenone, have been identified $[107,108]$, of which $\beta$-lapachone $(3,4$ dihydro-2,2-dimethyl-2H-naphtho[1,2-b]pyran-5,6-dione) is recently well studied as a strong substrate of NQO1 [109, 110]. $\beta$-Lapachone was first isolated from the bark of the Lapacho tree and was reported to inhibit tumor growth [111]. Several reports have indicated that pharmacological substrates of NQO1 ameliorate phenotypic manifestations associated with pathological conditions in rodent models. In particular, metabolic diseases such as obesity and spontaneous hypertension were shown to be reversed upon NQO1 enzymatic action using $\beta$-lapachone $[112,113]$, and pathological conditions such as arterial restenosis due to tissue injury and cisplatin-associated nephrotoxicity were also ameliorated by NQO1 enzymatic action using this substrate [11, 114]. As summarized in Figure 3, the increase of the cellular $\mathrm{NAD}^{+} / \mathrm{NADH}$ ratio by $\beta$-lapachone prevents cisplatin-induced kidney damage by modulation of potential damage mediators such as oxidative stress and inflammatory responses. Furthermore, $\beta$-lapachone did not interfere with the tumoricidal effect of cisplatin in vivo [11].

\section{Conclusion}

In conclusion, a NAD redox balance is critically important for sustaining a healthy condition, and maintenance of adequate NAD redox balance may show therapeutic benefits in various diseases through the regulation of $\mathrm{NAD}^{+}$-dependent enzymes and their downstream targets including SIRTs, PARPs, NF- $\kappa \mathrm{B}$, and $\mathrm{p} 53$. In this review we strongly suggest for the first time that direct modulation of a cellular NAD redox balance by pharmacological agents could be a promising therapeutic approach for the treatment of various diseases, including cisplatin nephrotoxicity.

\section{Conflict of Interests}

All authors declare no competing interests.

\section{Acknowledgment}

This work was supported by National Research Foundation of Korea (NRF) grants funded by the Korean government (MSIP): no. 2011-0028866 and no. 2011-0030130. 


\section{References}

[1] B. Rosenberg, L. Van Camp, and T. Krigas, "Inhibition of cell division in Escherichia coli by electrolysis products from a platinum electrode," Nature, vol. 205, no. 4972, pp. 698-699, 1965.

[2] D. Wang and S. J. Lippard, "Cellular processing of platinum anticancer drugs," Nature Reviews Drug Discovery, vol. 4, no. 4, pp. 307-320, 2005.

[3] S. M. Cohen and S. J. Lippard, "Cisplatin: from DNA damage to cancer chemotherapy," Progress in Nucleic Acid Research and Molecular Biology, vol. 67, pp. 93-130, 2001.

[4] I. Arany and R. L. Safirstein, "Cisplatin nephrotoxicity," Seminars in Nephrology, vol. 23, no. 5, pp. 460-464, 2003.

[5] Z. H. Siddik, "Cisplatin: mode of cytotoxic action and molecular basis of resistance," Oncogene, vol. 22, no. 47, pp. 7265-7279, 2003.

[6] N. Pabla and Z. Dong, "Cisplatin nephrotoxicity: mechanisms and renoprotective strategies," Kidney International, vol. 73, no. 9, pp. 994-1007, 2008.

[7] R. P. Miller, R. K. Tadagavadi, G. Ramesh, and W. B. Reeves, "Mechanisms of cisplatin nephrotoxicity," Toxins, vol. 2, no. 11, pp. 2490-2518, 2010.

[8] M. H. Hanigan and P. Devarajan, "Cisplatin nephrotoxicity: molecular mechanisms," Cancer Therapy, vol. 1, pp. 47-61, 2003.

[9] Y. Ido, "Pyridine nucleotide redox abnormalities in diabetes," Antioxidants \& Redox Signaling, vol. 9, no. 7, pp. 931-942, 2007.

[10] H.-J. Kim, G.-S. Oh, A. Shen et al., "Augmentation of NAD ${ }^{+}$by NQO1 attenuates cisplatin-mediated hearing impairment," Cell Death and Disease, vol. 5, no. 6, Article ID e1292, 2014.

[11] G.-S. Oh, H.-J. Kim, J.-H. Choi et al., "Pharmacological activation of NQO1 increases NAD ${ }^{+}$levels and attenuates cisplatinmediated acute kidney injury in mice," Kidney International, vol. 85, no. 3, pp. 547-560, 2014.

[12] N. Braidy, G. J. Guillemin, H. Mansour, T. Chan-Ling, A. Poljak, and R. Grant, "Age related changes in NAD+ metabolism oxidative stress and Sirtl activity in wistar rats," PLOS ONE, vol. 6, no. 4, Article ID e19194, 2011.

[13] H. Massudi, R. Grant, N. Braidy, J. Guest, B. Farnsworth, and G. J. Guillemin, "Age-associated changes in oxidative stress and NAD+ metabolism in human tissue," PLoS ONE, vol. 7, no. 7, Article ID e42357, 2012.

[14] H.-J. Kim, G.-S. Oh, S.-K. Choe, T. H. Kwak, R. Park, and H.-S. So, "NAD ${ }^{+}$metabolism in age-related hearing loss," Aging and Disease, vol. 5, no. 2, pp. 150-159, 2014.

[15] D. Chen, J. Bruno, E. Easlon et al., "Tissue-specific regulation of SIRT1 by calorie restriction," Genes and Development, vol. 22, no. 13, pp. 1753-1757, 2008.

[16] V. Adam-Vizi and L. Tretter, "The role of mitochondrial dehydrogenases in the generation of oxidative stress," Neurochemistry International, vol. 62, no. 5, pp. 757-763, 2013.

[17] M. P. Murphy, "How mitochondria produce reactive oxygen species," The Biochemical Journal, vol. 417, no. 1, pp. 1-13, 2009.

[18] M. Werner, M. J. Costa, L. G. Mitchell, and R. Nayar, "Nephrotoxicity of xenobiotics," Clinica Chimica Acta, vol. 237, no. 1-2, pp. 107-154, 1995.

[19] N. Pabla, R. F. Murphy, K. Liu, and Z. Dong, “The copper transporter Ctrl contributes to cisplatin uptake by renal tubular cells during cisplatin nephrotoxicity," American Journal of Physiology-Renal Physiology, vol. 296, no. 3, pp. F505-F511, 2009.
[20] G. Ciarimboli, "Membrane transporters as mediators of cisplatin side-effects," Anticancer Research, vol. 34, no. 1, pp. 547550, 2014.

[21] D. M. Townsend, K. D. Tew, L. He, J. B. King, and M. H. Hanigan, "Role of glutathione S-transferase Pi in cisplatininduced nephrotoxicity," Biomedicine and Pharmacotherapy, vol. 63, no. 2, pp. 79-85, 2009.

[22] R. D. Wainford, R. J. Weaver, K. N. Stewart, P. Brown, and G. M. Hawksworth, "Cisplatin nephrotoxicity is mediated by gamma glutamyltranspeptidase, not via a C-S lyase governed biotransformation pathway," Toxicology, vol. 249, no. 2-3, pp. 184-193, 2008.

[23] N. A. G. Santos, C. S. Catão, N. M. Martins, C. Curti, M. L. P. Bianchi, and A. C. Santos, "Cisplatin-induced nephrotoxicity is associated with oxidative stress, redox state unbalance, impairment of energetic metabolism and apoptosis in rat kidney mitochondria," Archives of Toxicology, vol. 81, no. 7, pp. 495-504, 2007.

[24] R. Çetin, E. Devrim, B. Kilicoglu, A. Avci, Ö. Çandir, and I. Durak, "Cisplatin impairs antioxidant system and causes oxidation in rat kidney tissues: possible protective roles of natural antioxidant foods," Journal of Applied Toxicology, vol. 26, no. 1, pp. 42-46, 2006.

[25] H. H. Szeto, "Mitochondria-targeted peptide antioxidants: novel neuroprotective agents," The AAPS Journal, vol. 8, no. 3, pp. E521-E531, 2006.

[26] C. E. Berry and J. M. Hare, "Xanthine oxidoreductase and cardiovascular disease: molecular mechanisms and pathophysiological implications," Journal of Physiology, vol. 555, no. 3, pp. 589-606, 2004.

[27] R. A. Gottlieb, "Cytochrome P450: major player in reperfusion injury," Archives of Biochemistry and Biophysics, vol. 420, no. 2, pp. 262-267, 2003.

[28] A. A. Miller, G. J. Dusting, C. L. Roulston, and C. G. Sobey, "NADPH-oxidase activity is elevated in penumbral and nonischemic cerebral arteries following stroke," Brain Research, vol. 1111, no. 1, pp. 111-116, 2006.

[29] H. Liu and R. Baliga, "Cytochrome P450 2E1 null mice provide novel protection against cisplatin-induced nephrotoxicity and apoptosis," Kidney International, vol. 63, no. 5, pp. 1687-1696, 2003.

[30] J. Bai and A. I. Cederbaum, "Mitochondrial catalase and oxidative injury," Biological Signals and Receptors, vol. 10, no. 34, pp. 189-199, 2001.

[31] M. Geiszt, "NADPH oxidases: new kids on the block," Cardiovascular Research, vol. 71, no. 2, pp. 289-299, 2006.

[32] M. T. Quinn, M. C. B. Ammons, and F. R. DeLeo, “The expanding role of NADPH oxidases in health and disease: no longer just agents of death and destruction," Clinical Science, vol. 111, no. 1, pp. 1-20, 2006.

[33] B. Bánfi, B. Malgrange, J. Knisz, K. Steger, M. Dubois-Dauphin, and K.-H. Krause, "NOX3, a superoxide-generating NADPH oxidase of the inner ear," The Journal of Biological Chemistry, vol. 279, no. 44, pp. 46065-46072, 2004.

[34] H.-J. Kim, J.-H. Lee, S.-J. Kim et al., "Roles of NADPH oxidases in cisplatin-induced reactive oxygen species generation and ototoxicity," Journal of Neuroscience, vol. 30, no. 11, pp. 39333946, 2010.

[35] G. Ramesh and W. B. Reeves, "Inflammatory cytokines in acute renal failure," Kidney International Supplement, vol. 66, no. 91, pp. S56-S61, 2004. 
[36] C. Y. Lu, J. Hartono, M. Senitko, and J. Chen, “The inflammatory response to ischemic acute kidney injury: a result of the 'right stuff' in the 'wrong place'?" Current Opinion in Nephrology and Hypertension, vol. 16, no. 2, pp. 83-89, 2007.

[37] G. Ramesh and W. Brian Reeves, "TNF- $\alpha$ mediates chemokine and cytokine expression and renal injury in cisplatin nephrotoxicity," The Journal of Clinical Investigation, vol. 110, no. 6, pp. 835-842, 2002.

[38] G. Ramesh, B. Zhang, S. Uematsu, S. Akira, and W. B. Reeves, "Endotoxin and cisplatin synergistically induce renal dysfunction and cytokine production in mice," American Journal of Physiology-Renal Physiology, vol. 293, no. 1, pp. F325-F332, 2007.

[39] B. Zhang, G. Ramesh, C. C. Norbury, and W. B. Reeves, "Cisplatin-induced nephrotoxicity is mediated by tumor necrosis factor- $\alpha$ produced by renal parenchymal cells," Kidney International, vol. 72, no. 1, pp. 37-44, 2007.

[40] Z. Dong and S. S. Atherton, "Tumor necrosis factor- $\alpha$ in cisplatin nephrotoxicity: a homebred foe?" Kidney International, vol. 72, no. 1, pp. 5-7, 2007.

[41] G. Ramesh and W. B. Reeves, "TNFR2-mediated apoptosis and necrosis in cisplatin-induced acute renal failure," American Journal of Physiology-Renal Physiology, vol. 285, no. 4, pp. F610-F618, 2003.

[42] P. D. Sánchez-González, F. J. López-Hernández, J. M. LópezNovoa, and A. I. Morales, "An integrative view of the pathophysiological events leading to cisplatin nephrotoxicity," Critical Reviews in Toxicology, vol. 41, no. 10, pp. 803-821, 2011.

[43] K. Tsuruya, T. Ninomiya, M. Tokumoto et al., "Direct involvement of the receptor-mediated apoptotic pathways in cisplatininduced renal tubular cell death," Kidney International, vol. 63, no. 1, pp. 72-82, 2003.

[44] E. Abraham, "Nuclear factor- $\kappa$ B and its role in sepsis-associated organ failure," Journal of Infectious Diseases, vol. 187, supplement 2, pp. S364-S369, 2003.

[45] G. Ramesh and W. B. Reeves, "p38 MAP kinase inhibition ameliorates cisplatin nephrotoxicity in mice," American Journal of Physiology-Renal Physiology, vol. 289, no. 1, pp. F166-F174, 2005.

[46] T. Yamakawa, S. Eguchi, T. Matsumoto et al., "Intracellular signaling in rat cultured vascular smooth muscle cells: roles of nuclear factor- $\kappa \mathrm{B}$ and $\mathrm{p} 38$ mitogen-activated protein kinase on tumor necrosis factor- $\alpha$ production," Endocrinology, vol. 140, no. 8, pp. 3562-3572, 1999.

[47] R. Medzhitov and C. A. Janeway Jr., "Decoding the patterns of self and nonself by the innate immune system," Science, vol. 296, no. 5566, pp. 298-300, 2002.

[48] H. Kono and K. L. Rock, "How dying cells alert the immune system to danger," Nature Reviews Immunology, vol. 8, no. 4, pp. 279-289, 2008.

[49] D. U. Ferreiro and E. A. Komives, "Molecular mechanisms of system control of NF- $\kappa \mathrm{B}$ signaling by $\mathrm{I} \kappa \mathrm{B} \alpha$," Biochemistry, vol. 49, no. 8, pp. 1560-1567, 2010.

[50] B. Zhang, G. Ramesh, S. Uematsu, S. Akira, and W. B. Reeves, "TLR4 signaling mediates inflammation and tissue injury in nephrotoxicity," Journal of the American Society of Nephrology, vol. 19, no. 5, pp. 923-932, 2008.

[51] G. Ramesh, S. R. Kimball, L. S. Jefferson, and W. B. Reeves, "Endotoxin and cisplatin synergistically stimulate TNF- $\alpha$ production by renal epithelial cells," American Journal of Physiology-Renal Physiology, vol. 292, no. 2, pp. F812-F819, 2007.
[52] A. F. McGettrick and L. A. J. O'Neill, "The expanding family of MyD88-like adaptors in Toll-like receptor signal transduction," Molecular Immunology, vol. 41, no. 6-7, pp. 577-582, 2004.

[53] A. Tsung, J. R. Klune, X. Zhang et al., "HMGB1 release induced by liver ischemia involves Toll-like receptor 4-dependent reactive oxygen species production and calcium-mediated signaling," Journal of Experimental Medicine, vol. 204, no. 12, pp. 29132923, 2007.

[54] R. H. Houtkooper, C. Cantó, R. J. Wanders, and J. Auwerx, "The secret life of $\mathrm{NAD}^{+}$: an old metabolite controlling new metabolic signaling pathways," Endocrine Reviews, vol. 31, no. 2, pp. 194-223, 2010.

[55] C. A. Elvehjem, R. J. Madden, F. M. Strong, and D. W. Wolley, "The isolation and identification of the anti-black tongue factor. 1937," The Journal of Biological Chemistry, vol. 277, no. 34, article e22, 2002.

[56] W. Ying, "NAD+/NADH and NADP+/NADPH in cellular functions and cell death: regulation and biological consequences," Antioxidants \& Redox Signaling, vol. 10, no. 2, pp. 179206, 2008.

[57] P. Belenky, K. L. Bogan, and C. Brenner, "NAD ${ }^{+}$metabolism in health and disease," Trends in Biochemical Sciences, vol. 32, no. 1, pp. 12-19, 2007.

[58] N. Dali-Youcef, M. Lagouge, S. Froelich, C. Koehl, K. Schoonjans, and J. Auwerx, "Sirtuins: the 'magnificent seven', function, metabolism and longevity," Annals of Medicine, vol. 39, no. 5, pp. 335-345, 2007.

[59] E. Michishita, J. Y. Park, J. M. Burneskis, J. C. Barrett, and I. Horikawa, "Evolutionarily conserved and nonconserved cellular localizations and functions of human SIRT proteins," Molecular Biology of the Cell, vol. 16, no. 10, pp. 4623-4635, 2005.

[60] B. J. North, B. L. Marshall, M. T. Borra, J. M. Denu, and E. Verdin, "The human Sir2 ortholog, SIRT2, is an NAD ${ }^{+}$ dependent tubulin deacetylase," Molecular Cell, vol. 11, no. 2, pp. 437-444, 2003.

[61] H. Vaziri, S. K. Dessain, E. Ng Eaton et al., "hSIR2(SIRT1) functions as an NAD-dependent p53 deacetylase," Cell, vol. 107, pp. 149-159, 2001.

[62] M. C. Haigis, R. Mostoslavsky, K. M. Haigis et al., "SIRT4 inhibits glutamate dehydrogenase and opposes the effects of calorie restriction in pancreatic $\beta$ cells," Cell, vol. 126, no. 5, pp. 941-954, 2006.

[63] G. Liszt, E. Ford, M. Kurtev, and L. Guarente, "Mouse Sir2 homolog SIRT6 is a nuclear ADP-ribosyltransferase," The Journal of Biological Chemistry, vol. 280, no. 22, pp. 21313-21320, 2005.

[64] S. Imai, F. B. Johnson, R. A. Marciniak, M. McVey, P. U. Park, and L. Guarante, "Sir2: an NAD-dependent histone deacetylase that connects chromatin silencing, metabolism, and aging," Cold Spring Harbor Symposia on Quantitative Biology, vol. 65, pp. 297-302, 2000.

[65] K. Hasegawa, S. Wakino, K. Yoshioka et al., "Sirtl protects against oxidative stress-induced renal tubular cell apoptosis by the bidirectional regulation of catalase expression," Biochemical and Biophysical Research Communications, vol. 372, no. 1, pp. 51-56, 2008.

[66] K. Hasegawa, S. Wakino, K. Yoshioka et al., "Kidney-specific overexpression of Sirtl protects against acute kidney injury by retaining peroxisome function," The Journal of Biological Chemistry, vol. 285, no. 17, pp. 13045-13056, 2010.

[67] D. H. Kim, Y. J. Jung, J. E. Lee et al., "Sirtl activation by resveratrol ameliorates cisplatin-induced renal injury through 
deacetylation of p53," American Journal of Physiology-Renal Physiology, vol. 301, no. 2, pp. F427-F435, 2011.

[68] M. Neumann and M. Naumann, "Beyond I $\kappa$ Bs: alternative regulation of NF- $\kappa$ B activity," The FASEB Journal, vol. 21, no. 11, pp. 2642-2654, 2007.

[69] F. Yeung, J. E. Hoberg, C. S. Ramsey et al., "Modulation of NF- $\kappa$ B-dependent transcription and cell survival by the SIRT1 deacetylase," The EMBO Journal, vol. 23, no. 12, pp. 2369-2380, 2004.

[70] T. Yoshizaki, J. C. Milne, T. Imamura et al., "SIRT1 exerts anti-inflammatory effects and improves insulin sensitivity in adipocytes," Molecular and Cellular Biology, vol. 29, no. 5, pp. 1363-1374, 2009.

[71] A. J. Levine and M. Oren, "The first 30 years of p53: growing ever more complex," Nature Reviews Cancer, vol. 9, no. 10, pp. 749-758, 2009.

[72] J.-P. Kruse and W. Gu, "Modes of p53 regulation," Cell, vol. 137, no. 4, pp. 609-622, 2009.

[73] Y. Tang, W. Zhao, Y. Chen, Y. Zhao, and W. Gu, "Acetylation is indispensable for p53 activation," Cell, vol. 133, no. 4, pp. 612626, 2008.

[74] C. L. Brooks and W. Gu, "The impact of acetylation and deacetylation on the p53 pathway," Protein and Cell, vol. 2, no. 6, pp. 456-462, 2011.

[75] S. Li, M. Banck, S. Mujtaba, M.-M. Zhou, M. M. Sugrue, and M. J. Walsh, "p53-Induced growth arrest is regulated by the mitochondrial SirT3 deacetylase," PLOS ONE, vol. 5, no. 5, Article ID e10486, 2010.

[76] W. Gu and R. G. Roeder, "Activation of p53 sequence-specific DNA binding by acetylation of the p53 C-terminal domain," Cell, vol. 90, no. 4, pp. 595-606, 1997.

[77] Y. Zhao, S. Lu, L. Wu et al., "Acetylation of p53 at lysine 373/382 by the histone deacetylase inhibitor depsipeptide induces

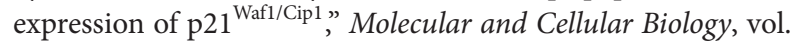
26, no. 7, pp. 2782-2790, 2006.

[78] A. Kotsinas, V. Aggarwal, E.-J. Tan, B. Levy, and V. G. Gorgoulis, "PIG3: a novel link between oxidative stress and DNA damage response in cancer," Cancer Letters, vol. 327, no. 1-2, pp. 97-102, 2012.

[79] J. D. Amaral, J. M. Xavier, C. J. Steer, and C. M. P. Rodrigues, "Targeting the p53 pathway of apoptosis," Current Pharmaceutical Design, vol. 16, no. 22, pp. 2493-2503, 2010.

[80] A. V. Vaseva and U. M. Moll, "The mitochondrial p53 pathway," Biochimica et Biophysica Acta (BBA)_Bioenergetics, vol. 1787, no. 5, pp. 414-420, 2009.

[81] L. Mouchiroud, R. H. Houtkooper, and J. Auwerx, "NAD" metabolism: a therapeutic target for age-related metabolic disease," Critical Reviews in Biochemistry and Molecular Biology, vol. 48, no. 4, pp. 397-408, 2013.

[82] R. Krishnakumar and W. L. Kraus, "The PARP side of the nucleus: molecular actions, physiological outcomes, and clinical targets," Molecular Cell, vol. 39, no. 1, pp. 8-24, 2010.

[83] C. Thomas and A. V. Tulin, "Poly-ADP-ribose polymerase: machinery for nuclear processes," Molecular Aspects of Medicine, vol. 34, no. 6, pp. 1124-1137, 2013.

[84] P. M. Goodwin, P. J. Lewis, M. I. Davies, C. J. Skidmore, and S. Shall, "The effect of gamma radiation and neocarzinostatin of NAD and ATP levels in mouse leukaemia cells," Biochimica et Biophysica Acta (BBA)_General Subjects, vol. 543, no. 4, pp. 576-582, 1978.
[85] C. J. Skidmore, M. I. Davies, P. M. Goodwin et al., "The involvement of poly(ADP-ribose) polymerase in the degradation of NAD caused by gamma-radiation and N-methyl-Nnitrosourea," European Journal of Biochemistry, vol. 101, no. 1, pp. 135-142, 1979.

[86] C. Cantó and J. Auwerx, "NAD" as a signaling molecule modulating metabolism," Cold Spring Harbor Symposia on Quantitative Biology, vol. 76, pp. 291-298, 2011.

[87] V. Launay-Vacher, J.-B. Rey, C. Isnard-Bagnis, G. Deray, and M. Daouphars, "Prevention of cisplatin nephrotoxicity: state of the art and recommendations from the European Society of Clinical Pharmacy Special Interest Group on Cancer Care," Cancer Chemotherapy and Pharmacology, vol. 61, no. 6, pp. 903909, 2008.

[88] G. Losonczy, C. Máthé, V. Müller, K. Szondy, and J. Moldvay, "Incidence, risk factors and prevention of cisplatin-induced nephrotoxicity in patients with lung cancer," Magyar Onkologia, vol. 54, no. 4, pp. 289-296, 2010.

[89] T. Araki, Y. Sasaki, and J. Milbrandt, "Increased nuclear NAD biosynthesis and SIRT1 activation prevent axonal degeneration," Science, vol. 305, no. 5686, pp. 1010-1013, 2004.

[90] W. Ying, G. Wei, D. Wang et al., "Intranasal administration with $\mathrm{NAD}^{+}$profoundly decreases brain injury in a rat model of transient focal ischemia," Frontiers in Bioscience, vol. 12, no. 7, pp. 2728-2734, 2007.

[91] V. B. Pillai, N. R. Sundaresan, G. Kim et al., "Exogenous NAD blocks cardiac hypertrophic response via activation of the SIRT3-LKB1-AMP-activated kinase pathway," The Journal of Biological Chemistry, vol. 285, no. 5, pp. 3133-3144, 2010.

[92] P. Bai, C. Cantó, H. Oudart et al., "PARP-1 inhibition increases mitochondrial metabolism through SIRT1 activation," Cell Metabolism, vol. 13, no. 4, pp. 461-468, 2011.

[93] I. A. Ayoub, E. Jian Lee, C. S. Ogilvy, M. F. Beal, and K. I. Maynard, "Nicotinamide reduces infarction up to two hours after the onset of permanent focal cerebral ischemia in Wistar rats," Neuroscience Letters, vol. 259, no. 1, pp. 21-24, 1999.

[94] I. A. Ayoub and K. I. Maynard, "Therapeutic window for nicotinamide following transient focal cerebral ischemia," NeuroReport, vol. 13, no. 2, pp. 213-216, 2002.

[95] K. L. Brewer and J. S. Hardin, "Neuroprotective effects of nicotinamide after experimental spinal cord injury," Academic Emergency Medicine, vol. 11, no. 2, pp. 125-130, 2004.

[96] S. Kaneko, J. Wang, M. Kaneko et al., "Protecting axonal degeneration by increasing nicotinamide adenine dinucleotide levels in experimental autoimmune encephalomyelitis models," Journal of Neuroscience, vol. 26, no. 38, pp. 9794-9804, 2006.

[97] A. A. Sauve, "NAD" and vitamin $\mathrm{B}_{3}$ : from metabolism to therapies," The Journal of Pharmacology and Experimental Therapeutics, vol. 324, no. 3, pp. 883-893, 2008.

[98] W. Ying, P. Garnier, and R. A. Swanson, "NAD" repletion prevents PARP-1-induced glycolytic blockade and cell death in cultured mouse astrocytes," Biochemical and Biophysical Research Communications, vol. 308, no. 4, pp. 809-813, 2003.

[99] W. Ying, C. C. Alano, P. Garnier, and R. A. Swanson, "NAD+ as a metabolic link between DNA damage and cell death," Journal of Neuroscience Research, vol. 79, no. 1-2, pp. 216-223, 2005.

[100] A. Gaikwad, D. J. Long II, J. L. Stringer, and A. K. Jaiswal, "In vivo role of $\mathrm{NAD}(\mathrm{P}) \mathrm{H}$ :Quinone Oxidoreductase 1 (NQO1) in the regulation of intracellular redox state and accumulation of abdominal adipose tissue," The Journal of Biological Chemistry, vol. 276, pp. 22559-22564, 2001. 
[101] D. Ross, J. K. Kepa, S. L. Winski, H. D. Beall, A. Anwar, and D. Siegel, "NAD $(\mathrm{P}) \mathrm{H}$ :quinone oxidoreductase 1 (NQO1): chemoprotection, bioactivation, gene regulation and genetic polymorphisms," Chemico-Biological Interactions, vol. 129, no. 1-2, pp. 77-97, 2000.

[102] M. Gao, A. Singh, K. Macri et al., "Antioxidant components of naturally-occurring oils exhibit marked anti-inflammatory activity in epithelial cells of the human upper respiratory system," Respiratory Research, vol. 12, article 92, 2011.

[103] D. K. Gessner, R. Ringseis, M. Siebers et al., "Inhibition of the pro-inflammatory NF- $\kappa \mathrm{B}$ pathway by a grape seed and grape marc meal extract in intestinal epithelial cells," Journal of Animal Physiology and Animal Nutrition, vol. 96, no. 6, pp. 1074-1083, 2012.

[104] R. Pazdro and J. R. Burgess, “The antioxidant 3H-1,2-dithiole3-thione potentiates advanced glycation end-product-induced oxidative stress in SH-SY5Y cells," Experimental Diabetes Research, vol. 2012, Article ID 137607, 8 pages, 2012.

[105] C. I. Jones III, H. Zhu, S. F. Martin, Z. Han, Y. Li, and B. R. Alevriadou, "Regulation of antioxidants and phase 2 enzymes by shear-induced reactive oxygen species in endothelial cells," Annals of Biomedical Engineering, vol. 35, no. 5, pp. 683-693, 2007.

[106] O. Moscovitz, P. Tsvetkov, N. Hazan et al., "A mutually inhibitory feedback loop between the $20 \mathrm{~S}$ proteasome and its regulator, NQO1," Molecular Cell, vol. 47, no. 1, pp. 76-86, 2012.

[107] R. H. Haefeli, M. Erb, A. C. Gemperli et al., "NQo1-dependent redox cycling of idebenone: effects on cellular redox potential and energy levels," PLoS ONE, vol. 6, no. 3, Article ID e17963, 2011.

[108] X. Huang, Y. Dong, E. A. Bey et al., "An NQO1 substrate with potent antitumor activity that selectively kills by PARP1induced programmed necrosis," Cancer Research, vol. 72, no. 12, pp. 3038-3047, 2012.

[109] A. B. Pardee, Y. Z. Li, and C. J. Li, "Cancer therapy with $\beta$ lapachone," Current Cancer Drug Targets, vol. 2, no. 3, pp. 227$242,2002$.

[110] L. S. Li, E. A. Bey, Y. Dong et al., "Modulating endogenous NQO1 levels identifies key regulatory mechanisms of action of $\beta$-lapachone for pancreatic cancer therapy," Clinical Cancer Research, vol. 17, no. 2, pp. 275-285, 2011.

[111] S. M. Planchon, S. Wuerzberger, B. Frydman et al., “ $\beta$ Lapachone-mediated apoptosis in human promyelocytic leukemia (HL-60) and human prostate cancer cells: a p53independent response," Cancer Research, vol. 55, no. 17, pp. 3706-3711, 1995.

[112] J. H. Hwang, D. W. Kim, E. J. Jo et al., "Pharmacological stimulation of NADH oxidation ameliorates obesity and related phenotypes in mice," Diabetes, vol. 58, no. 4, pp. 965-974, 2009.

[113] Y.-H. Kim, J. H. Hwang, J.-R. Noh et al., "Activation of $\mathrm{NAD}(\mathrm{P}) \mathrm{H}$ :quinone oxidoreductase ameliorates spontaneous hypertension in an animal model via modulation of eNOS activity," Cardiovascular Research, vol. 91, no. 3, pp. 519-527, 2011.

[114] S.-Y. Kim, N. H. Jeoung, C. J. Oh et al., "Activation of $\mathrm{NAD}(\mathrm{P}) \mathrm{H}$ :quinone oxidoreductase 1 prevents arterial restenosis by suppressing vascular smooth muscle cell proliferation," Circulation Research, vol. 104, no. 7, pp. 842-850, 2009. 


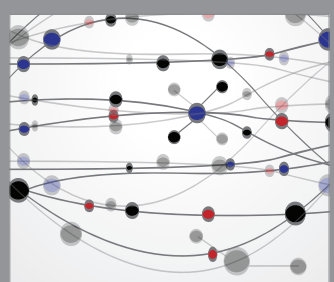

The Scientific World Journal
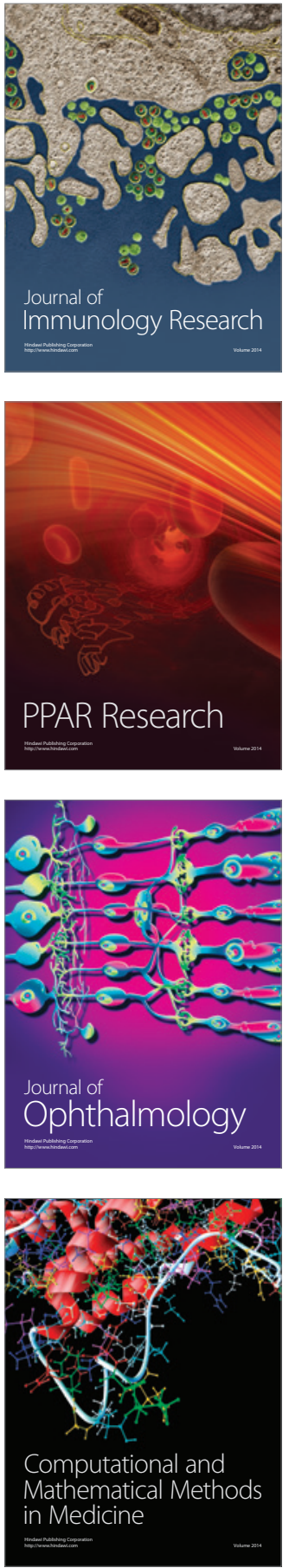

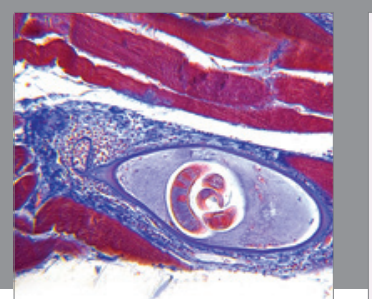

Gastroenterology Research and Practice

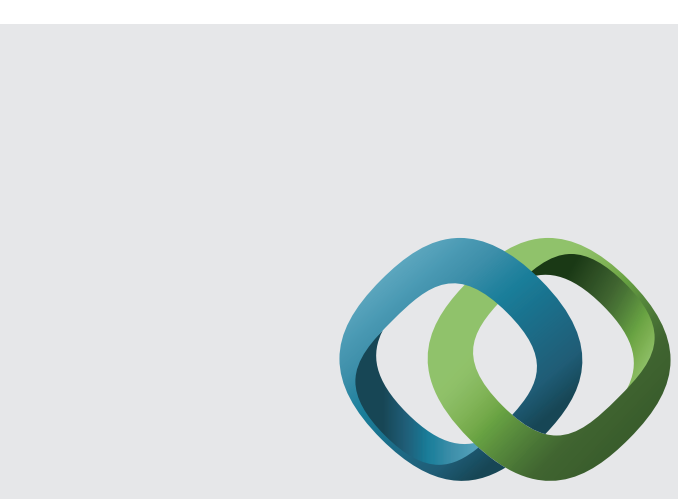

\section{Hindawi}

Submit your manuscripts at

http://www.hindawi.com
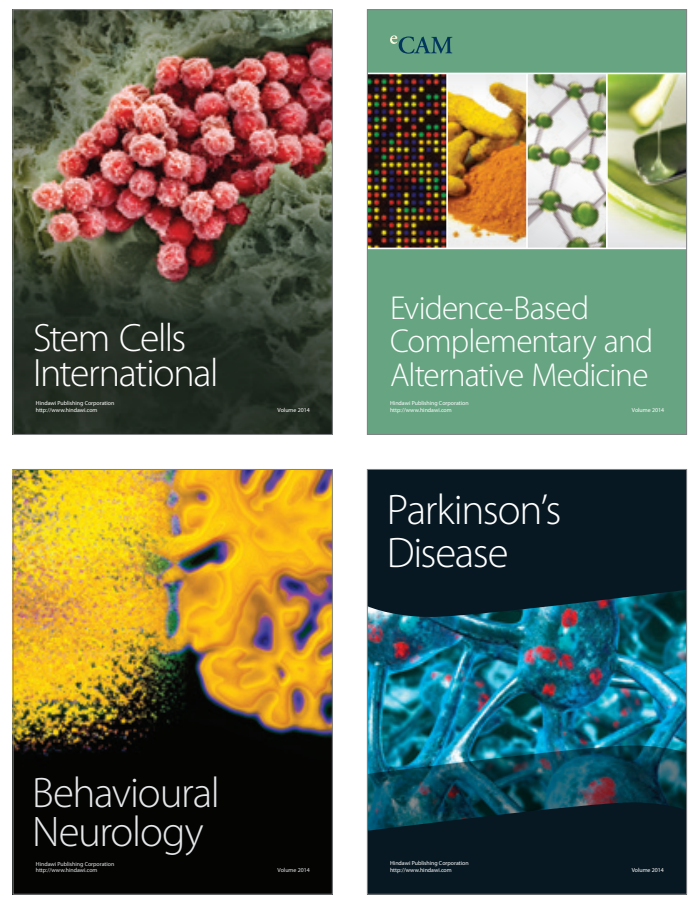
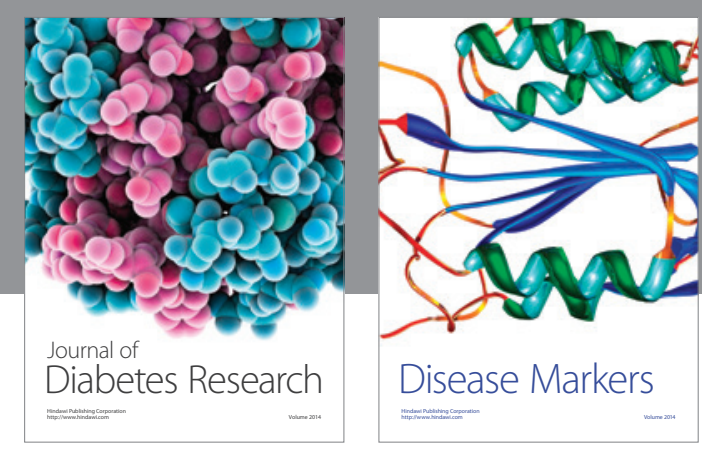

Disease Markers
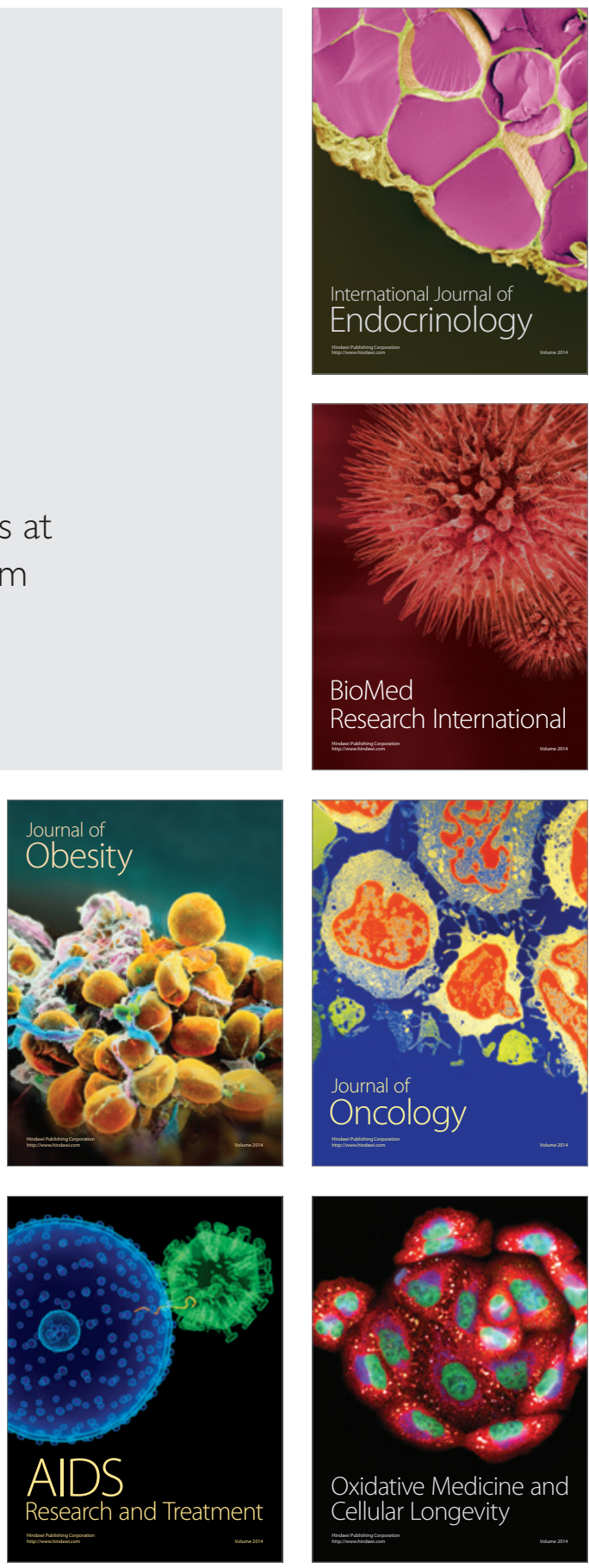